\title{
LA DESCODIFICACIÓN DEL DEREGHO GIVIL EN CHILE A LA LUZ DE LAS NORMAS DEL TÍTULO XXXV DEL LIBRO IV DEL CÓDIGO GIVIL
}

\author{
Veronika Wegner Astudillo ${ }^{1}$
}

\begin{abstract}
RESUMEN
El presente trabajo estudia el fenómeno de la descodificación a la luz de las normas sobre responsabilidad civil extracontractual contenidas en el Código Civil chileno, atendida la proliferación de disposiciones sobre responsabilidad aquiliana contenidas en leyes especiales, contrastando estas últimas con los principios contenidos en el Código Civil, a fin de determinar si es posible sostener que a este respecto ha operado una verdadera descodificación; y de ser afirmativa esta última cuestión, cuál sería hoy la regla general en materia de factores de atribución de responsabilidad.
\end{abstract}

Palabras clave: Descodificación, responsabilidad extracontractual, responsabilidad aquiliana, factores de atribución.

\section{INTRODUGGIÓN}

Mucho se ha escrito acerca de la descodificación del derecho y -sobre todo- del derecho civil. ${ }^{2}$ El primero en acuñar el concepto fue el profesor Natalino IRTI, quien auguró -ya en 1978- que la nuestra sería una época de la descodificación ${ }^{3}$ y que el derecho fijado en códigos devendría en residual.

El presente trabajo trata el aludido concepto a la luz de un ámbito específico del derecho civil: ${ }^{4}$ la responsabilidad extracontractual, regulada en el Código de

1 Universidad Adolfo Ibáñez, Viña del Mar, Chile (veronika.wegner@uai.cl).

2 En Chile, por todos, destacamos las obras de Guzmán Brito (1993), pp. 39-62; y de Figueroa Yáñez (2005), pp. 101-116.

3 IRTI (1992).

4 En este sentido, son muchas y diversas las normas civiles dictadas con posterioridad al código de Bello: "[e]n materia de personas y familia pueden mencionarse la primitiva ley de matrimonio civil, hoy reemplazada por otra más moderna, pero que trata de idéntica materia; las leyes que mejoraron la situación de los hijos naturales y, luego, igualaron a todos los hijos; la que autorizó el cambio de nombres; la que entregó plena capacidad a la mujer casada; diferentes leyes sobre adopción y sobre trasplantes de órganos. En materia de derechos reales, tuvimos la ley de Reforma Agraria, que alteró profundamente las disposiciones sobre expropiación de predios rústicos; y tenemos las leyes sobre 
Bello en el Libro IV, título XXXV, artículos 2314 y siguientes, contrastando la proliferación de normas sobre responsabilidad aquiliana contenidas en leyes especiales con los principios contenidos en el Código Civil sobre esta materia, a fin de determinar si es posible afirmar que a este respecto ha operado una descodificación; y de ser afirmativa esta última cuestión, cuál sería hoy la regla general en materia de factores de atribución de responsabilidad.

Para esta tarea, nos referiremos a las nociones de codificación y descodificación, para que -luego de tratar las formas de materialización de esta última-, establecer cuál es el sentido en que utilizaremos la expresión descodificación. En otro apartado, se establecerá cuál es la ratio de las normas contenidas en el Código Civil a propósito de la responsabilidad extracontractual, para contrastarla con los casos de responsabilidad extracontractual contenidos en normas periféricas, a fin de responder si a este respecto se verifica alguna forma de descodificación. Finalmente formularemos las conclusiones a que arribemos luego de este estudio.

\section{AGERGA DE LA NOGIÓN DE GODIFIGAGIÓN}

Hablar de descodificación supone - por cierto- tratar primeramente acerca de la codificación como forma de fijación del derecho. ${ }^{5}$ En palabras de Figueroa, la codificación corresponde a una "presentación sistemática, organizada de manera sintética y metodológica de un cuerpo de reglas generales y permanentes que rigen en una o varias esferas particulares del derecho en un país determinado". ${ }^{6}$

Esta especie de fijación "se caracteriza por innovar respecto de la presentación del material normativo y su organización, por establecer un derecho nuevo que se distancia del anterior, y por determinar la pérdida de vigencia de todas las disposiciones jurídicas anteriores, aunque puedan ser compatibles con la legislación codificada".?

$\mathrm{Al}$ respecto, Barros ${ }^{8}$ reconoce dos métodos de codificación: uno formal y otro material. Respecto del primero, la codificación civil "responde al propósito de ordenar sistemáticamente las normas relativas a un extenso ámbito de relaciones privadas, que nacen de la familia, de la propiedad, del acto y del hecho jurídico, incluida

propiedad intelectual e industrial, regularización de la pequeña propiedad raíz y copropiedad inmobiliaria, mientras en materia de contratos tenemos las leyes sobre arrendamientos urbanos y rurales, operaciones de crédito de dinero, prenda agraria, prenda industrial y prenda sin desplazamiento, y sobre derecho del consumo y protección del consumidor. La lista es larga y compleja". FiguerOA YÁÑez (2005), p. 105. Nosotros nos centraremos sólo en las normas extravagantes de responsabilidad civil extracontractual.

5 Sobre el particular, vid. GuZmán (1977).

6 Figueroa Yáñez (2005), traducción del autor del concepto de Vogel, p. 101.

7 Corral Talciani (2005), p. 642.

8 Barros Bourie (2005), pp. 151-161. 
la muerte. En tal sentido, el Derecho Civil está codificado en un sentido formal". ${ }^{9}$ En cuanto al segundo - esto es, el sentido material- "[p]uede entenderse por tal un ordenamiento que responde a un cierto sistema 'interno', porque está articulado en torno a principios normativos y a categorías conceptuales, y que usualmente consolida los cambios, por lo general incrementales, aunque en ciertos lugares críticos suelen ser discretos, introducidos por la jurisprudencia con el auxilio de la doctrina jurídica". ${ }^{10}$

En Chile el inicio del proceso de codificación puede situarse en 1822 con la idea de O’Higgins de traducir los códigos napoleónicos, abriendo así un debate en torno a la sustitución del derecho heredado de la monarquía para establecer un derecho propio. De esta forma, luego de fallidos intentos, culminó solitariamente la tarea Andrés Bello, aprobándose y promulgándose en 1855 el Código Civil de la República de Chile: el primer código nacional. Continuó este movimiento codificador con el Código de Comercio (1865); el Código Penal (1874); la Ley de Organización y Atribuciones de los Tribunales (Código Orgánico de Tribunales); el Código de Minería (1874); el Código de Procedimiento Civil (1902); y el Código de Procedimiento Penal (1906). A este período clásico, siguió la codificación de ramas más sectoriales y modernas, como el derecho sanitario (1918); derecho del trabajo (1931); derecho tributario (1960) y aeronáutico (1990). ${ }^{11}$

\section{LA IDEA DE DESGODIFICAGIÓN Y SU GONSEGUENGIA EN EL DEREGHO GOMÚN}

Al fenómeno de codificación anterior siguió -según es afirmado por algunos“un largo período que se ha llamado de 'descodificación' de las normas civiles, caracterizado por la fragmentación y dispersión de dichas normas en diferentes cuerpos legales". ${ }^{12}$ Esta dispersión normativa de reglas civiles se explica porque el código no pudo preverlo todo, y se hizo necesaria la regulación de actividades cada vez más complejas y específicas. ${ }^{13}$

Para IRTI, esta situación se traduce en distintas fases históricas: “[e]n la primera, la norma general es todavía el derecho del mayor número de casos, y la norma especial se restringe a la regulación de los casos provistos de datos diferenciadores. En la segunda, extendiéndose a criterios de la norma especial a otras normas especiales, y ensanchándose la franja de destinatarios de ésta, la norma general se degrada a derecho residual, o del menor número de casos. En la tercera y última, los criterios de regulación, introducidos por la norma especial, revisten también a la hipótesis

9 Barros Bourie (2005), p. 151.

10 Barros Bourie (2005), pp. 152-153.

11 Vid. GuZmán Brito (1982).

12 Figueroa Yáñez (2005), p. 101.

13 " $[\mathrm{N}]$ o se puede aspirar a que un código se haga cargo de las mil preguntas que plantea la aplicación práctica de cada instituto; ni que regule los estatutos jurídicos especiales, que en gran parte se soportan en las reglas y principios generales de la disciplina” [BARRos BourIE (2005), p. 159]. 
más amplia y llegan a ser el contenido de una nueva norma general, respecto a la que puede reabrirse el ciclo ahora trazado". ${ }^{14}$ Así, "[l]as leyes especiales regulan materias e instituciones fuera o contra el Código Civil. Promulgadas para la realización de los principios constitucionales, o nacidas de 'estatutos de grupos', las leyes especiales ya no son 'especificantes' respecto al Código Civil, sino que obedecen a lógicas autónomas, y hablan lenguajes y jergas sectoriales. Para determinadas materias o categorías de relaciones, el Derecho del Código Civil asume carácter residual, en el sentido de intervenir cuando los recursos normativos especiales se han explotado y agotado". ${ }^{15}$

Este fenómeno tendría múltiples factores: “[e]n primer lugar la complejidad y multiplicidad de necesidades sociales exigen al legislador la sanción de normas especiales que satisfagan los problemas que se van devengando de las relaciones humanas. La jurisprudencia, en segundo lugar, atribuyó distintas interpretaciones a los menajes normológicos del legislador y creó nuevas instituciones extrañas a nuestros cuerpos legales". ${ }^{16}$

Consecuencia directa de lo anterior es la pérdida del Código Civil como continente del derecho general para pasar a tomar el lugar de derecho residual, como recipiente de principios y lógicas de aplicación particular, sufriendo una inversión de su función: "[ya no consiste en una] disciplina de supuestos de hecho más amplios, sino de supuestos de hecho vacíos, desprovistos, a saber, de aquellos elementos de hecho, de aquellas notas características, que suscitan el surgimiento de nuevos principios en leyes especiales" ${ }^{17}$.

\section{DE LAS FORMAS DE DESCODIFICAGIÓN Y DEL SENTIDO EN QUE OGUPAREMOS ESTA EXPRESIÓN}

Se han señalado como manifestaciones de este fenómeno, entre otras:

a) "La pérdida del valor y utilidad del Código como instrumento técnico de fijación del Derecho";

b) "La pérdida de aplicabilidad del Código a los conflictos privados por la proliferación de leyes especiales que se superponen a sus normas"18;

c) "El apartamiento de la jurisprudencia de los tribunales de las normas del Código para poder hacer frente a realidades nuevas, respecto de las cuales las disposiciones legales se presentan como obsoletas y anacrónicas”,

14 IRTI (1992), p. 52.

$15 \operatorname{IrTi}(1992)$, p. 117.

16 Frontera (2009), p. 104.

17 IRTI, (1992), p. 33.

18 En esta parte seguimos el esquema planteado por Corral Talcians, (2005), pp. 641-651.

19 Corral Talciani, (2005), pp. 641-651. Sobre este interesante punto, vid. Couailler (2005), pp. 117-131. El autor explica cómo a través de la interpretación judicial se produjo una "inflación legislativa" a partir de las normas del Code sobre responsabilidad civil extracontractual: "El derecho 
Para Irti, la descodificación se traduce en relegar al Código Civil a la categoría de microsistema por la proliferación de leyes especiales: "[e]l ordenamiento jurídico ya no coincide con un solo conjunto de normas, con la antigua y decimonónica constelación que tenía en el centro el Código civil y sobre éste gravitaba el movimiento de las leyes especiales. El Código Civil es ahora uno de los sistemas, de que se compone el gran universo del Derecho privado. Otros núcleos de normas, roto cualquier nexo con el Código civil, se constituyen en sistema y se desarrollan según lógicas de sector". ${ }^{20}$

No obstante, lo anterior, se le critica al autor no haber otorgado relevancia en su estudio a la noción de leyes singulares, así como por equiparar el concepto de ley especial para referirse tanto a aquellas disposiciones que regulan lo normado en el Código Civil, aunque de manera diferente, como a aquellas que rigen lo desconocido por él. Para Guzmán Brito "la verdadera 'descodificación' se produce no por obra de las leyes de derecho especial, sino de las de derecho singular", ${ }^{21}$ de forma que sólo establecidos y diferenciados los conceptos de leyes especiales ${ }^{22}$ y singulares ${ }^{23}$ es posible afinar el concepto de descodificación. Y esta podría verificarse de tres modos: (i) formal; (ii) material y formal; y (iii) material.

La primera se refiere a la creación de derecho especial y nuevo, generando proliferación de leyes en torno al Código, pero sin desconocer su ratio; la segunda corresponde al establecimiento de derecho singular a través de leyes extravagantes o fuera del Código; y finalmente la descodificación material se produce a través de la creación de derecho singular que lleva a la modificación de las normas del mismo. Luego “la verdadera 'descodificación' es la material, sea o no formal; ella incide en la lógica de la generalidad del sistema jurídico incluido en el código, sea que las nor-

de la responsabilidad delictual y cuasidelictual, tan apresurada y parsimoniosamente tratado por el Código Civil - unas veinte líneas en tres artículos- se enriqueció profundamente en el transcurso de una extensa construcción de tipo pretoriano con las teorías del riesgo, las teorías de la causalidad directa e indirecta, la teoría del abuso del derecho, la definición de custodia de la cosa, de su papel activo o pasivo, de los criterios de la custodia de la estructura, de la custodia del comportamiento, de la custodia colectiva, precisó la noción de fuerza mayor, etc., viniendo la ley de 1985 a precisar todas las reglas de responsabilidad e indemnización en caso de accidentes de tráfico.” (p. 127). En Chile el fenómeno podría repetirse con la interpretación extensiva que hace la jurisprudencia de los artículos 2320 y 2322 a las personas jurídicas y a los trabajadores del estado. Este particular excede nuestro estudio. Vid. Corral Talciani (2013), p. 233 y ss.

$20 \operatorname{IrTI}(1992)$, p. 63.

21 GuZMán Brito (1993), p. 44.

22 Existe una relación de especialidad-generalidad: "una hipótesis es endosistemáticamente especial respecto de otra, que entonces es general, cuando la nota agregada y que especializa a la primera, pertenece al sistema en que está insertada la hipótesis que es general respecto de la especializada" [GuZMán Brito (1993), p. 45].

23 Existe una relación de singularidad-regularidad: "[la] hipótesis es exosistemáticamente especial respecto de otra, que es entonces general, cuando la nota agregada que especializa a la primera no pertenece al sistema al que pertenece la hipótesis que es general respecto de la especializada" [GuzMÁN BRITO (1993), p. 45]. 
mas resulten introducidas en el articulado, sea que permanezcan fuera de él". ${ }^{24}$ La descodificación se produce cuando se desconoce el sentido del sistema incorporado en el código, cuando las nuevas normas escapan su lógica o principios.

Es precisamente en este último sentido en el que utilizaremos la expresión descodificación.

\section{AGERGA DE LA RATIO GONTENIDA EN LAS NORMAS DEL TÍTULO XXXV DEL LIBRO IV DEL GÓDIGO GIVIL}

En materia de hechos ilícitos civiles, nuestro Código contempla en el Libro IV un apartado especial -Título XXXV "De los delitos y cuasidelitos"- en el que desarrolla detallada y casuísticamente la responsabilidad civil extracontractual en veintiún artículos.

Para determinar cuál es el factor de atribución en este caso, debe tenerse presente que, en un modelo subjetivo de responsabilidad, la falta de cuidado o la intención positiva de causar injuria en la persona o propiedad de otro es lo que impone al agente la obligación de indemnizar los daños que causa, ya sea por no adoptar las medidas tendientes a evitar el daño o por su especial ánimo de causarlos.

Así, "[e]xiste un deber genérico de diligencia cuando las normas del sistema imponen el deber de obrar con el cuidado y la prudencia que exigieren las circunstancias de persona, tiempo y lugar; o como se afirma en el ámbito anglosajón, cuando se tiene el deber de actuar como lo haría un hombre razonable. Por su parte, existe un deber particular de diligencia cuando las normas ordenan la realización de una conducta específica, como conducir a menos de una determinada velocidad o la adopción de medidas concretas [...]. En este último caso, la infracción de la norma concreta permite afirmar que el agente fue negligente o culpable". ${ }^{25}$ Mientras que en el caso de la responsabilidad objetiva, estricta o sin culpa, la obligación de indemnizar del agente no proviene de la falta de diligencia o de un especial ánimo al momento de ejecutar la conducta o la omisión que provoca los daños a la víctima. En este sentido, como indica Papayanis, "[1]a obligación de compensar puede basarse en el riesgo propio de la actividad que realiza el agente o en la peligrosidad de los objetos de que se sirve. También podría fundarse en el beneficio que el agente obtiene de la actividad generadora de daños. Lo relevante aquí es comprender que la responsabilidad objetiva no se activa por la violación de ningún estándar de conducta. Solo requiere la existencia de un nexo de causalidad [...] entre el riesgo que introduce la actividad y el daño". ${ }^{26}$

24 GuZmán Brito (1993), p. 49.

25 Papayannis (2014), p. 32.

26 Papayannis (2014), p. 32. 
Establecido lo anterior, de la simple lectura y revisión de las normas del Título XXXV podemos afirmar que, sin perjuicio de que las nociones principales en materia de responsabilidad en general son la culpa, la causalidad y el daño, ${ }^{27}$ es culpa $^{28}$ la idea sobre la cual se desarrolla el sistema de atribución de responsabilidad del Código Civil:

a) Art. 2314, "El que ha cometido un delito o cuasidelito que ha inferido daño a otro, es obligado a la indemnización...”. ${ }^{29}$ El legislador pone énfasis en la subjetividad: no basta con inferir un daño a otro, sino que el hecho voluntario que lo origina debe provenir de una intención positiva o bien de una acción u omisión negligente;

b) Art. 2319, a propósito de la capacidad delictual, se excluye a los menores de siete años y a los dementes, pero se establece la responsabilidad de las personas a cuyo cargo estén, en la medida que a éstas "pudiere imputárseles negligencia"; 30

c) Art. 2320, acerca de la presunción de culpa del principal por las personas que se encuentran a su cargo. El precepto contempla una norma liberatoria de responsabilidad, probándose de parte de quienes son responsables por otros que no existió falta de cuidado; esto es, "si con la autoridad y cuidado que su respectiva calidad les confiere y prescribe, no hubieren podido impedir el hecho"; ${ }^{31}$

d) Art. 2321, sobre responsabilidad de los padres por los hechos dañosos de sus hijos menores que "conocidamente provengan de mala educación, o de los hábitos viciosos que les han dejado adquirir". Los padres tienen el deber de criar y educar a de sus hijos, de modo que "si el hijo ha sido mal educado o ha adquirido tales hábitos, quiere decir que aquellos no han cumplido con esta obligación; hay pues, una culpa manifiesta del padre o madre a cuyo cuidado está el hijo, y nada puede explicar o excusar"; 32

e) Art. 2322, a propósito de la presunción de culpa que recae sobre los amos por el hecho de sus criados domésticos. Al igual que en el caso del artículo 2320 se establece una norma liberatoria de responsabilidad "si se probare que [...] han ejercido [sus funciones] de un modo impropio que los amos no tenían medio de prever o impedir, empleando el cuidado ordinario, y la autoridad competente". ${ }^{33}$

f) Art. 2326, con ocasión de los daños provocados por un animal, se responsabiliza a su dueño o su encargado, "salvo que la soltura, extravío o daño no pueda

27 TAPIA Rodríguez (2005), p. 280.

28 Sin perjuicio de los casos en que esta se presume (arts. 2320, 2321, 2322, 2327, 2328 del Código Civil).

29 El destacado es nuestro.

30 El destacado es nuestro.

31 El destacado es nuestro.

32 Alessandri Rodríguez (2005), pp. 92-93.

33 El destacado es nuestro. 
imputarse a la culpa del dueño o del dependiente encargado de la guarda o servicio del animal". ${ }^{34}$ Continúa la disposición indicando que esta regla se aplica a toda persona que se sirva de un animal ajeno, "salva su acción contra el dueño, si el daño ha sobrevenido por una calidad o vicio del animal, que el dueño con mediano cuidado o prudencia debió conocer o prever, y de lo que no le dio conocimiento". ${ }^{35}$

g) Art. 2327, presume la culpa del tenedor de un animal fiero que causa daño, cuando éste no reporta utilidad para la guarda o servicio de un predio, siendo el perjuicio causado "siempre imputable al que lo tenga" ${ }^{36}$ de acuerdo a la citada disposición: "el hecho de tener en un predio un animal fiero [...] constituye culpa por sí solo. Como ésta existe mientras el animal permanezca en el predio, porque no la constituye la falta de vigilancia del animal, sino el hecho de tener en él un animal inútil y peligroso, le será imposible a su dueño, poseedor o tenedor probar lo contrario". ${ }^{37-38}$

h) Art. 2329, que establece en su inciso primero el principio de la reparación integral del daño, que se funda nuevamente en la culpa o dolo del agente: "todo daño que pueda imputarse a malicia o negligencia de otra persona, debe ser reparado por ésta"; 39 y luego en los numerales de su inciso segundo - para la mayor parte de la doctrina- se contendrían casos de presunciones de culpa por el hecho propio ${ }^{40} \mathrm{y}$

i) Art. 2333, concede acción popular en caso de daño contingente que "por imprudencia o negligencia de alguien amenace a personas indeterminadas". ${ }^{41}$

Como bien señala Alessandri, la teoría adoptada por nuestro Código Civil es la "clásica de la responsabilidad subjetiva en toda su amplitud; la teoría del riesgo no la admite en caso alguno. No podía ser de otro modo si se considera que fue dictado en una época -1855- en que nadie discutía si se ponía en duda la necesidad de la culpa o dolo de parte del autor del daño para comprometer su responsabilidad". ${ }^{2}$

34 El destacado es nuestro.

35 El destacado es nuestro.

36 El destacado es nuestro.

37 Alessandri Rodríguez (2005), p. 93.

38 En contra, Corral TAlciani (2013), p. 246. Para el autor se trataría de un caso de "responsabilidad objetiva o sin culpa, que, a modo de sanción, la ley establece en contra de quien, sin necesidad, mantiene un animal peligroso".

39 El destacado es nuestro.

40 En contra, Corral Talciani (2013) quien entiende que los casos mencionados en el artículo 2329 no contienen presunciones de culpa, sino de causalidad: "la culpa debe ser objeto de prueba, pero la relación de causalidad entre la conducta negligente (disparar el arma, remover las losas, tener en mal estado el acueducto o puente) y el daño causado (muerte o lesión de una persona) se tiene por establecida (se presume legalmente), mientras no se demuestre lo contrario" (p. 227).

41 El destacado es nuestro.

42 Alessandri Rodríguez (2005), pp. 91-92. 
De forma que el sistema de atribución de responsabilidad del Código se funda en la prueba de la culpa del agente, siendo esto común a todo el derecho occidental, ${ }^{43}$ sin perjuicio de los casos en que ella se presume. ${ }^{44}$

\section{DE LOS REGÍMENES DE RESPONSABILIDAD NO CONTEM- PLADOS EN EL GÓDIGO GIVIL}

En Chile, fuera del Código Civil, y sin tener la pretensión de exhaustividad, podemos identificar las siguientes normas relativas a la responsabilidad civil extracontractual que regulan regímenes de responsabilidad en particular:

a) Responsabilidad extracontractual del Estado y de las Municipalidades (Constitución Política de la República, Leyes Nº 18.575 y Nº 18.695);

b) Responsabilidad civil por accidentes del trabajo y enfermedades profesionales (Ley $\mathrm{N}^{\circ}$ 16.744);

c) Responsabilidad civil por vicios en la construcción (Decreto con fuerza de Ley $\mathrm{N}^{\circ} 458$ de 1975);

d) Responsabilidad civil por los derrames de hidrocarburos (Decreto Ley No 2.222 de 1978);

e) Responsabilidad civil por uso de plaguicidas (Decreto Ley No3557 de 1980);

f) Responsabilidad extracontractual de los directores de las sociedades anónimas (Ley $\mathrm{N}^{\circ}$ 18.046);

43 Corral Talciani (2013), p. 89. Históricamente, podemos situar en el derecho romano las primeras nociones acerca de la indemnización por daños, con la lex aquilia, que suponía sólo daños para su procedencia. Con posterioridad y bajo la influencia del cristianismo, el derecho medieval establece un sistema de atribución de responsabilidad basado en la culpa personal, abandonándose el modelo romano por el final del siglo XIV. Serán los juristas franceses Domat - desarrollando la obra del iusnaturalista GROCiO- y PothiER quienes elaborarán el llamado régimen clásico de responsabilidad civil que pasará a los artículos 1382, 1383 y 1384 del Code y luego a nuestro Código Civil, como en todas las legislaciones inspiradas en el código de Napoleón. Corral TALCiani (2013), pp. 75-82.

44 A saber: (i) artículo 2320 inciso primero, regla general de presunción de culpa a propósito del hecho de terceros; (ii) artículo 2320 inciso segundo, presunción de culpa del padre o madre por el hecho de los hijos menores que habiten en la misma casa; (iii) artículo 2320 inciso tercero, presunción de culpa del tutor o curador por la conducta del pupilo que vive bajo su dependencia y cuidado; (iv) artículo 2320 inciso cuarto primera parte, presunción de culpa de los jefes de colegios y escuelas por los hechos de sus discípulos; (v) artículo 2320 inciso cuarto segunda parte, presunción de responsabilidad de los artesanos y empresarios por el hecho de sus aprendices o dependientes; (vi) artículo 2321, presunción de responsabilidad de los padres por los hechos de los hijos menores que conocidamente provengan de su mala educación o los hábitos viciosos que los han dejado adquirir; (vii) artículo 2322, presunción de responsabilidad de los "amos" por la conducta de sus empleados domésticos; (viii) artículo 2327, presunción de responsabilidad del tenedor de un animal fiero que no reporta utilidad; (ix) artículo 2328, presunción de responsabilidad de las personas que habitan la parte de un edificio, por las cosas que se caen o arrojan; y (x) artículo 2329, presunción de culpa en el hecho propio. 
g) Responsabilidad por daños nucleares (Ley $\mathrm{N}^{\circ} 18.302$ );

h) Responsabilidad civil por accidentes aéreos (Código Aeronáutico);

i) Responsabilidad civil por daños al medio ambiente (Ley $\left.\mathrm{N}^{\circ} 19.300\right)$;

j) Responsabilidad civil por productos defectuosos (Ley $\mathrm{N}^{\circ} 19.496$ );

k) Responsabilidad civil médica en establecimientos de salud pública (Ley $\left.\mathrm{N}^{\circ} 19.966\right)$;

1) Responsabilidad civil por almacenamiento de datos personales (Ley $\left.\mathrm{N}^{\circ} 19.628\right)$

m) Responsabilidad civil derivada de la actividad periodística (Ley $\mathrm{N}^{\circ} 19.733$ )

n) Responsabilidad civil extracontractual por accidentes de tránsito (Ley $\left.\mathrm{N}^{\circ} 18.290\right)$; etc.

Ahora bien, como ya hemos dicho, no basta la simple proliferación de normas para hablar de descodificación, a lo menos en su sentido verdadero. ${ }^{45}$ De forma que para responder si existe una descodificación material de la responsabilidad extracontractual contenida en el Código Civil es necesario analizar la cuestión desde la perspectiva de la culpa en sentido amplio, de forma que toda vez que estemos frente a un régimen de responsabilidad estricta ${ }^{46} \mathrm{O}$ sin culpa se verificará un alejamiento de la ratio de las reglas del Título XXXV.

\section{ANÁLISIS DE LAS NORMAS SOBRE RESPONSABILIDAD EX- TRAGONTRAGTUAL GONTENIDAS EN LEYES EXTRAVAGAN- TES $^{47}$}

a)Responsabilidad extracontractual del Estado y de las Municipalidades. Las normas fundamentales en esta materia se encuentran en la Constitución Política de la República, artículos $6^{\circ}, 7^{\circ}$ y 38 . La responsabilidad del Estado se funda en la noción de falta de servicio, cuyo factor de atribución es la culpa ${ }^{48}$.

45 Guzmán Brito (1993), p. 49. En contra, Figueroa Yáñez (2005), pp. 104-106.

46 "El antecedente normativo de la responsabilidad estricta es la realización de una actividad o la tenencia de una cosa que genera el riesgo de daño. En circunstancias que la calificación de la conducta efectiva del autor del daño resulta indiferente, lo determinante es que el daño se produzca en el ámbito de riesgo sujeto a responsabilidad estricta" [BARROs BOURIE (2006), p. 475].

47 En el sentido dado en GuZmán Brito, (1993), p. 48 y siguientes.

48 Fundada en la falta de servicio. Para Corral, estas disposiciones "establecen una responsabilidad directa $[\ldots]$, pero no de carácter objetivo absoluto y fundada en la sola causalidad material del daño, sino en un factor de imputación denominado 'falta de servicio'. De esta manera, puede hablarse de una responsabilidad estricta (objetiva) calificada: el demandante debe probar la falta de servicio, además del daño y la causalidad, para obtener la condena del Estado u otros órganos públicos a responder civilmente". Corral Talciani (2013), p. 320-321. 
Así, en el Decreto con fuerza de ley $\mathrm{N}^{\circ} 1$ de 17 de noviembre de $2001^{49}$, que fija el texto refundido, coordinado y sistematizado de la Ley $\mathrm{N}^{\circ} 18.575$, orgánica constitucional de bases generales de la administración del Estado, se establece en su artículo $4^{\circ}$ que "[e]l Estado será responsable por los daños que causen los órganos de la Administración en el ejercicio de sus funciones, sin perjuicio de las responsabilidades que pudieren afectar al funcionario que los hubiere ocasionado".

Luego queda de manifiesto que la responsabilidad civil extracontractual del Estado descansa sobre la noción de culpa cuando el artículo 42 inciso segundo dispone que el Estado tiene derecho a repetir en contra del funcionario "que hubiere incurrido en falta personal".

Por su parte, el Decreto con fuerza de ley $\mathrm{N}^{\circ} 1$ de 2006, que fija el texto refundido, coordinado y sistematizado de la Ley $\mathrm{N}^{\circ} 18.695$, orgánica constitucional de municipalidades, de 26 de julio de 2006, ${ }^{50}$ recoge el mismo principio en su artículo 152: "Las municipalidades incurrirán en responsabilidad por los daños que causen, la que procederá principalmente por falta de servicio", concluyendo que no obstante lo anterior, éstas "tendrán derecho a repetir en contra del funcionario que hubiere incurrido en falta personal".

En todo caso, la falta personal debe acreditarse y alude a una conducta imprudente o dolosa del funcionario, siguiendo las reglas del sistema subjetivo de imputación de responsabilidad.

b) Responsabilidad civil por accidentes del trabajo y enfermedades profesionales. Se regula esta materia en la Ley $\mathrm{N}^{\circ} 16.744$, que establece normas sobre accidentes del trabajo y enfermedades profesionales, de 1 de febrero de $1968 .^{51} \mathrm{Su}$ artículo $1^{\circ}$ establece la obligatoriedad del seguro social contra los riesgos de accidentes del trabajo y enfermedades profesionales, mientras que el artículo 69 establece el régimen de imputación de responsabilidad frente a los daños que se provoquen al trabajador. Para estos efectos, la indemnización es exigible con prescindencia de si hubo o no culpa del empleador, excluyéndose la posibilidad de reclamarla en los "accidentes debidos a fuerza mayor extraña que no tenga relación alguna con el trabajo y los producidos intencionalmente por la víctima" (art. $5^{\circ}$ inciso final).

Si bien - en principio- podría pensarse que esta ley establece un caso de responsabilidad estricta o sin culpa, tal conclusión se encuentra desvirtuada por lo dispuesto en su artículo 69 letra a): "Cuando, el accidente o enfermedad se deba a culpa o dolo de la entidad empleadora o de un tercero, sin perjuicio de las acciones criminales que procedan, deberán observarse las siguientes reglas: a) El organismo administrador tendrá derecho a repetir en contra del responsable del accidente, por

49 Última modificación 5 de enero de 2016, Ley N²0.880.

50 Última modificación 1 de abril de 2014, Ley N²0.742.

51 Última modificación 21 de abril de 2015, Ley N²0.830. 
las prestaciones que haya otorgado o deba otorgar". Junto con lo anterior, la letra b) del citado artículo establece la posibilidad de reclamar acción civil, de conformidad a las reglas del derecho común, por lo que la remisión a las normas generales de atribución de responsabilidad por negligencia es evidente. ${ }^{52}$

c) Responsabilidad civil por vicios en la construcción. Si bien las reglas generales en esta materia se contienen en el Código Civil, artículos 2323 y 2324, ${ }^{53}$ que fundan la atribución de responsabilidad en la negligencia del constructor, el Decreto con fuerza de ley N 458 de 1975, que aprueba nueva Ley General de Urbanismo y Construcciones, de 13 de abril de 1976, ${ }^{54}$ establece normas especiales. En efecto, señala su artículo 18 inciso $1^{\circ}$ que "[e]l propietario primer vendedor de una construcción será responsable de todos los daños y perjuicios que provengan de fallas o defectos en ella, sea durante su ejecución o después de terminada, sin perjuicio de su derecho a repetir en contra de quienes sean responsables de las fallas o defectos de construcción que hayan dado origen a los daños y perjuicios". Asimismo, establece la responsabilidad del propietario por los daños que sufran terceros como consecuencia de las fallas o defectos de la construcción.

Se trata de una responsabilidad sin culpa, que supone la prueba del vicio o defecto en la construcción y del daño, para hacer procedente la indemnización de perjuicios. Para Corral, se trataría de "una responsabilidad objetiva pero no absoluta sino derivada de la prueba de la falla o defecto de construcción y de la causalidad entre esta falla o defecto y el perjuicio alegado". ${ }^{55}$

d) Responsabilidad civil por los derrames de hidrocarburos. Regula esta materia el Decreto Ley No 2.222, que sustituye la Ley de Navegación, de 31 de mayo de 1978. El citado decreto establece un límite de responsabilidad (artículo 145) y la obligación de suscribir un seguro o caución por los siniestros que afecten a las naves o artefactos navales que midan más de tres mil toneladas (artículo 146). La responsabilidad en este caso es estricta. Así se desprende del artículo $144 \mathrm{~N}^{\circ} 2$, que dispone que "[e]l propietario, armador u operador de la nave o artefacto naval será responsable de los daños que se produzcan"; cuando impide la exoneración de responsabilidad fundada en la culpa exclusiva de los dependientes del dueño, armador u operador o las de la dotación; y cuando presume que el derrame o vertimiento de sustancias contaminantes del medio ambiente marino produce daño ecológico ( $\left.\mathrm{N}^{\circ} 5\right)$.

Se trata de un régimen de responsabilidad sin culpa ${ }^{56}$ por lo que existe a este respecto una descodificación material y formal.

52 En este sentido Corral Talciani (2013), p. 252.

53 Se responde por los daños ocasionados de la ruina del edificio "acaecida por haber omitido las necesarias reparaciones, o por haber faltado de otra manera al cuidado de un buen padre de familia".

54 Última modificación 26 de mayo de 2017, Ley No21.014.

55 Corral Talciani (2013), p. 276.

56 En el mismo sentido, Corral Talciani (2013), p. 144. 
e) Responsabilidad civil por uso de plaguicidas. Sistematiza esta responsabilidad el Decreto Ley N³.557 de 1981, que establece disposiciones sobre protección agrícola, de 9 de febrero de $1981 .{ }^{57} \mathrm{El}$ artículo 36 de esta ley sanciona la actividad cuando se produce daño a terceros, incluso en ausencia de culpa: "Si al aplicar plaguicidas se causaren daños a terceros, ya sea en forma accidental o como consecuencia inevitable de la aplicación, éstos podrán demandar judicialmente la indemnización de perjuicios correspondiente dentro del plazo de un año contado desde que se detecten los daños. En todo caso, no podrán ejercerse estas acciones una vez que hayan transcurrido cuatro años desde la aplicación del plaguicida”.

Constituye este caso un tipo de responsabilidad estricta o sin culpa, que escapa de la ratio de las normas del Código Civil. ${ }^{58}$

f) Responsabilidad extracontractual de los directores de sociedades anónimas. Norma esta materia la Ley $\mathrm{N}^{\circ} 18.046$, sobre sociedades anónimas, de 22 de octubre de 1981, ,9 $^{59}$ estableciendo una regla general de responsabilidad en el artículo 41. Dispone esta norma en su inciso primero que "[l] os directores deberán emplear en el ejercicio de sus funciones el cuidado y diligencia que los hombres emplean ordinariamente en sus propios negocios y responderán solidariamente de los perjuicios causados a la sociedad y a los accionistas por sus actuaciones dolosas o culpables".

El sistema de atribución de esta normativa se encuentra fundado en la culpa. Incluso se establece una presunción de ella, en casos de incumplimiento de la ley, su reglamento, los estatutos sociales o las normas que imparta la Superintendencia (artículo 133). La descodificación, por tanto, es simplemente formal.

g) Responsabilidad por daños nucleares. Se reglamenta esta cuestión en la Ley $\mathrm{N}^{\circ} 18.302$ sobre seguridad nuclear, de 2 de mayo de $1984 .{ }^{60}$ Señala el artículo 49 que "[1]a responsabilidad civil por daños nucleares será objetiva y estará limitada en la forma que establece esta ley". La responsabilidad en este caso es estricta o sin culpa y tarifada. Inclusive se pone de cargo del explotador el riesgo por el caso fortuito y la fuerza mayor en el artículo 56, salvo "los daños nucleares producidos por un accidente nuclear que se deba directamente a hostilidades de conflicto armado exterior, insurrección o guerra civil". Se establece, además -en su artículo 62- la obligación de caucionar la responsabilidad del explotador mediante seguros. Esta regulación escapa de la lógica de las reglas del Código Civil, verificándose una descodificación formal y material.

h) Responsabilidad civil por accidentes aéreos. Se refiere a esta materia el Código Aeronáutico. ${ }^{61}$ En lo pertinente, dispone el artículo 143 que "[e]l transportador

57 Última modificación 27 de diciembre de 2008, Ley N²0.308.

58 En el mismo sentido, Barros Bourie (2006), pp. 470-471.

59 Última modificación 29 de octubre de 2016, Ley N²0.954.

60 Última modificación 3 de diciembre de 2009, Ley N²0.402.

61 Ley N¹8.916 de 8 de febrero de 1990. Última modificación 30 de abril de 2015, Ley N²0.831. 
estará obligado a indemnizar la muerte o lesiones causadas a los pasajeros durante su permanencia a bordo de la aeronave o durante la operación de embarque o desembarque". La ley no exige culpa o dolo en la producción de los daños. En consecuencia, este se trataría de un caso de responsabilidad sin culpa por el riesgo creado. Se regulan casos específicos de daños a los pasajeros con ocasión de la infracción del contrato de transporte en los artículos 147 a 149, ambos inclusive. ${ }^{62}$ Respecto de los daños a terceros, tiene aplicación el artículo 155 que dispone la indemnización de los daños a las personas que se encuentren en la superficie "por el solo hecho de que emanen de la acción de una aeronave en vuelo, o por cuanto de ella caiga o se desprenda".

En este caso, nuevamente la responsabilidad del explotador es estricta o sin culpa: "por el solo hecho" de la operación de una aeronave en vuelo. Se verifica una descodificación formal y material.

i) Responsabilidad civil por daño al medio ambiente. Trata esta cuestión la Ley $\mathrm{N}^{\circ}$ 19.300, que aprueba Ley sobre Bases Generales del Medio Ambiente, de 9 de marzo de 1994. ${ }^{63}$ La regla general se contiene en el artículo $3^{\circ}$ de la ley: "Sin perjuicio de las sanciones que señale la ley, todo el que culposa o dolosamente cause daño al medio ambiente, estará obligado a repararlo materialmente, a su costo, si ello fuere posible, e indemnizarlo en conformidad a la ley". Esta idea se repite en los artículos 51 y siguientes. La referida disposición establece una remisión a las normas del Código Civil en materia de responsabilidad extracontractual y exige en su inciso primero - siguiendo la ratio del código- negligencia o dolo en el actuar del responsable: "Todo el que culposa o dolosamente cause daño ambiental responderá del mismo en conformidad a la presente ley". Establece además una presunción de culpa contra legalidad en el artículo 52 inciso primero. En efecto, señala la disposición que "[s]e presume legalmente la responsabilidad del autor del daño ambiental, si existe infracción a las normas de calidad ambiental, a las normas de emisiones, a los planes de prevención o de descontaminación, a las regulaciones especiales para los casos de emergencia ambiental o a las normas sobre protección, preservación o conservación ambientales, establecidas en la presente ley o en otras disposiciones legales o reglamentarias".

62 Artículo 147 "La indemnización por retardo en la ejecución del transporte de pasajeros no excederá de doscientas cincuentas unidades de fomento por cada uno de ellos".

"Sin embargo, no procederá esta indemnización si el transportador probare que adoptó las medidas necesarias para evitar el hecho causante del retardo, o que le fue imposible adoptarlas".

Artículo 148 "La destrucción, pérdida o avería del equipaje que se produjere durante el transporte aéreo de éste, o el retardo en su transporte, serán indemnizados con una cantidad equivalente a cuarenta unidades de fomento por cada pasajero".

Artículo 149 "La destrucción, pérdida o avería de la mercadería que se produjere durante el transporte aéreo de ella o por retardo en su transporte, serán indemnizadas con una cantidad que no exceda de una unidad de fomento por kilógramo de peso bruto de la carga".

63 Última modificación 1 de junio de 2016, Ley N²0.920. 
La descodificación en este caso es simplemente formal. ${ }^{64}$

j) Responsabilidad civil por productos defectuosos. Regula esta responsabilidad la Ley $\mathrm{N}^{\circ}$ 19.496, que establece normas sobre protección de los derechos de los consumidores, de 7 de marzo de $1997 .{ }^{65}$

La norma fundamental en esta materia es el artículo 22 que prescribe que "[1] os productos que los proveedores, siendo éstos distribuidores o comerciantes, hubieren debido reponer a los consumidores y aquellos por los que devolvieron la cantidad recibida en pago, deberán serles restituidos, contra su entrega, por la persona de quien los adquirieron o por el fabricante o importador, siendo asimismo de cargo de estos últimos el resarcimiento, en su caso, de los costos de restitución o de devolución y de las indemnizaciones que se hayan debido pagar en virtud de sentencia condenatoria, siempre que el defecto que dio lugar a una u otra les fuere imputable". De modo que la responsabilidad se funda en la culpa del proveedor, siguiendo las reglas del Código de Bello en materia de hechos ilícitos civiles. ${ }^{66}$

$\mathrm{Al}$ igual que en el caso anterior, la descodificación es simplemente formal.

k) Responsabilidad civil médica en establecimientos de salud pública. A propósito de esta materia específica, se aprobó la Ley $\mathrm{N}^{\circ}$ 19.966, que establece un régimen de garantías en salud, de 3 de septiembre de 2004. ${ }^{67}$ Como señalábamos a propósito de la responsabilidad del Estado y de las Municipalidades, el factor de atribución es la culpa del agente con base en la noción de falta de servicio. En lo pertinente dispone el artículo 38 de esta ley que "[1] os órganos de la Administración del Estado en materia sanitaria serán responsables de los daños que causen a particulares por falta de servicio" y añade que "[e]l particular deberá acreditar que el daño se produjo por la acción u omisión del órgano, mediando dicha falta de servicio".

Esta normativa sigue el sistema clásico de atribución de responsabilidad del Título XXXV, por lo que la descodificación es formal, en el sentido ya visto a propósito de la responsabilidad civil extracontractual del Estado.

l) Responsabilidad civil por almacenamiento de datos personales. El artículo 11 de la Ley $\mathrm{N}^{\circ} 19.628$ sobre protección de la vida privada, de 28 de agosto de $1999,{ }^{68}$ establece la procedencia de la acción indemnizatoria en contra del responsable de los registros o bases donde se almacenan datos personales. En el particular, se exige al custodio que -con posterioridad a la recolección de los datos- se cuide de ellos "con la debida diligencia, haciéndose responsable de los daños". En este caso, la descodificación es simplemente formal. Por otro lado, el artículo 23 de la citada

64 No obstante, lo anterior, para algunos se contendría en el artículo 53 de la citada ley, un caso de responsabilidad estricta. Vid. TAPIA Rodríguez (2005), pp. 322-323. En contra Barros Bourie (2006), p. 471.

65 Última modificación 17 de noviembre de 2016, Ley Nº 20.967.

66 En el mismo sentido, Corral Talciani (2013), p. 267.

67 Última modificación 24 de abril de 2012, Ley No 20.584.

68 Última modificación 17 de febrero de 2012, Ley No 20.575. 
ley, dispone que "[l]a persona natural o jurídica privada o el organismo público responsable del banco de datos personales deberá indemnizar el daño patrimonial y moral que causare por el tratamiento indebido de los datos, sin perjuicio de proceder a eliminar, modificar o bloquear los datos de acuerdo a lo requerido por el titular o, en su caso, lo ordenado por el tribunal". Para Corral, "[e]l tono imperativo del precepto 'deberá indemnizar' podría hacernos pensar que estamos ante un nuevo caso de responsabilidad objetiva o sin culpa. Pero debemos rechazar esta interpretación por varias razones, entre ellas porque la responsabilidad configurada en el art. 23 es una responsabilidad derivada de un ilícito infraccional y éste sólo procede cuando se acredita el elemento subjetivo y puesto que el vocablo 'indebido' revela, atendida a la historia del establecimiento del precepto, que se quería que se aplicaran los criterios comunes del Código Civil, esto es, la responsabilidad por culpa". ${ }^{69}$

m) Responsabilidad civil derivada de la actividad periodística. La Ley $\mathrm{N}^{\circ} 19.733$ sobre libertades de opinión e información y ejercicio del periodismo de 4 de junio de $2001,{ }^{70}$ establece en su artículo 40 que "[1]a acción civil para obtener la indemnización de daños y perjuicios derivada de delitos penados en esta ley se regirá por las reglas generales". En este sentido, se remite a las reglas del Título XXXV del Código Civil, produciéndose una descodificación formal, y no material..$^{11}$

n) Responsabilidad civil extracontractual por accidentes de tránsito. La Ley $\mathrm{N}^{\circ}$ 18.290, que fija el texto refundido, coordinado y sistematizado de la Ley de Tránsito, de 29 de octubre de 200972 establece en su artículo 165 la responsabilidad por el hecho propio basado en la culpa del agente e incorpora la noción de culpa contra legalidad. ${ }^{73}$

Así, dispone que "[t]oda persona que conduzca un vehículo en forma de hacer peligrar la seguridad de los demás, sin consideración de los derechos de éstos o infringiendo las reglas de circulación o de seguridad establecidas en esta ley, será responsable de los perjuicios que de ello provengan".

69 Corral Talciani (2013), p. 282

70 Última modificación 23 de diciembre de 2013, Ley No 20.709.

71 Con la salvedad que la remisión a estas normas difiere en lo que al inciso segundo del artículo 40 se refiere. Señala esta disposición que "La comisión de los delitos de injuria y calumnia a que se refiere el artículo 29, dará derecho a indemnización por el daño emergente, el lucro cesante y el daño moral", a diferencia de lo señalado en el artículo 2331 del Código Civil, que restringe la indemnización en caso de imputaciones injuriosas contra el honor o el crédito de una persona a daños de carácter pecuniario.

72 Última modificación 16 de marzo de 2016, Ley No 20.904. Esta normativa debe vincularse a la Ley $\mathrm{N}^{\circ} 18.490$, que establece seguro obligatorio de accidentes personales causados por la circulación de vehículos motorizados, de 4 de enero de 1986 (última modificación 9 de enero de 2014, Ley $\mathrm{N}^{\circ}$ 20.720) con límite de responsabilidad, sin perjuicio de las indemnizaciones que se persigan del civilmente responsable de acuerdo a las normas del Código Civil (artículo 15).

73 Siempre que exista relación de causalidad entre la infracción y el daño provocado por el accidente (artículo 166). 
Además, los artículos 167 y 168 establecen presunciones de responsabilidad de los conductores en los casos que estas normas indican. Si bien hasta este punto, la ley sigue las reglas de responsabilidad señaladas en el Código Civil, la situación cambia cuando se trata del dueño del vehículo o tenedor del mismo a cualquier título. Preceptúa el inciso segundo del artículo 169 que "a menos que estos últimos acrediten que el vehículo fue usado contra su voluntad, son solidariamente responsables de los daños o perjuicios que se ocasionen con su uso, sin perjuicio de la responsabilidad de terceros de conformidad a la legislación vigente".

La responsabilidad que pesa sobre el dueño del vehículo es estricta, por el hecho ajeno, produciéndose una nueva descodificación en su sentido formal y material.

\section{GONGLUSIONES}

En un aspecto cuantitativo, existe en la materia que analizamos una evidente proliferación de normas fuera del Código Civil. Consecuencia de ello, se produce una 'descodificación formal', que - como hemos señalado- no constituye una real o verdadera descodificación.

En gran parte de los casos estudiados, podemos observar que, junto con establecerse un régimen sectorial de responsabilidad a través de la regulación de materias especiales, con principios y lógicas propias, distintas de la ratio contenida en el código, se verifica una descodificación formal y material. Así ocurre en la responsabilidad civil por vicios en la construcción, por los derrames de hidrocarburos, por uso de plaguicidas, por daños nucleares, por accidentes aéreos y de tránsito.

No obstante lo anterior, ¿es posible hablar de descodificación y de recodificación como remedio ${ }^{74}$ ¿Es la responsabilidad objetiva la regla supletoria en nuestro ordenamiento? ¿Se ha transformado la responsabilidad subjetiva en el derecho extravagante?

Si bien concordamos con Papayannis en el sentido que "lógicamente la responsabilidad por culpa comprende a la responsabilidad estricta, porque no hay hipótesis en que se responda por negligencia y no se habría respondido bajo un estatuto de responsabilidad estricta", ${ }^{75}$ generalidad no es lo mismo que supletoriedad. ${ }^{76}$

Creemos que a pesar de la efectiva existencia de normas que se alejan del sentido del Código, no alcanzan a marginalizarlo, sino que - por el contrario- refuerzan el carácter de derecho común y general.

Pensamos que, no obstante, la propagación de normas extravagantes y singulares, el código mantiene su función de derecho supletorio y no ha devenido en residual. Como bien señala Tapia "ninguna de estas leyes especiales provocó la des-

74 Vid. Figueroa YáÑez (2005), pp. 104-106.

75 Papayannis (2014), p. 320.

76 Papayannis (2014), p. 311. 
trucción de la unidad civil creada por el Código, porque sus principios ideológicos fundamentales -libertad, igualdad y voluntad - no fueron sustituidos por otros, y permanecen, más aún, como una conquista democrática. Una descodificación verdadera supondría un reemplazo de estas categorías por otras, cuestión que no se percibe en la evolución que se ha trazado del Código Civil". ${ }^{77}$ 


\section{BIBLIOGRAFÍA CITADA}

Alessandri Rodríguez, Arturo (2005), De la responsabilidad extracontractual en el derecho civil chileno (Editorial Jurídica de Chile).

Barros Bourie, Enrique (2005), Sentidos y métodos de la codificación del derecho, en De la codificación a la descodificación. Code Civil (1804-2004). Código de Bello (1855-2005), Cuadernos de análisis jurídicos, Colección de Derecho Privado II, pp. 151-161

Barros Bourie, Enrique (2006), Tratado de responsabilidad extracontractual (Editorial Jurídica de Chile).

Couailler, Michel (2005), De la descodificación en la jurisprudencia francesa. Mirada de un juez, en De la codificación a la descodificación. Code Civil (1804-2004). Código de Bello (1855-2005), Guadernos de análisis jurídicos, Colección de Derecho Privado II, pp. 117-131.

Corral Talciani, Hernán (2005), "La descodificación del Derecho Civil en Chile, en El Código Civil de Chile 1855-2005”, en Trabajos expuestos en el Congreso Internacional celebrado para conmemorar su promulgación, pp. 641-651.

Corral Talciani, Hernán (2013), Lecciones de Responsabilidad civil extracontractual, $2^{a}$ edición, (2 $2^{\text {a }}$ edición, Thomson Reuters,).

Figueroa YÁÑEz, Gonzalo (2005), "Codificación, descodificación, recodificación del derecho civil, en De la codificación a la descodificación. Code Civil (18042004). Código de Bello (1855-2005)", en Cuadernos de análisis jurídicos, Colección de Derecho Privado II, pp. 101-116

Frontera, Juan Carlos (2009), "Descodificación civil argentina. Primeras Reflexiones", en Ambiente furídico No 11, pp. 95-106.

Guzmán Brito, Alejandro (1977), La fjación del Derecho (Ediciones Universitarias de Valparaíso, Universidad Católica de Valparaíso).

Guzmán Brito, Alejandro (1982), Andrés Bello codificador. Historia de la fijación y codificación del derecho civil en Chile (Ediciones de la Universidad de Chile).

GuzMán Brito, Alejandro (1993), "Codificación, descodificación y recodificación del Derecho Civil chileno", en Revista de Derecho y Jurisprudencia Vol. 90, T. 2, pp. 39-62.

IRTI, Natalino (1992), La edad de la descodificación, (trad. e introducción de Luis Rojo Ajuria, J.M. Bosch). 
Papayannis, Diego M. (2014), Comprensión y justificación de la responsabilidad extracontractual, (Marcial Pons).

Tapia Rodríguez, Mauricio (2005), Código Civil 1855-2005. Evolución y perspectivas (Editorial Jurídica de Chile). 


\section{NORMAS GITADAS}

Ley $\mathrm{N}^{\circ}$ 16.744, que establece normas sobre accidentes del trabajo y enfermedades profesionales.

Ley $\mathrm{N}^{\circ}$ 18.046, sobre sociedades anónimas.

Ley $\mathrm{N}^{\circ}$ 18.290, que fija el texto refundido, coordinado y sistematizado de la Ley de Tránsito.

Ley $\mathrm{N}^{\circ} 18.302$ sobre seguridad nuclear.

Ley $N^{\circ}$ 19.300, que aprueba Ley sobre Bases Generales del Medio Ambiente.

Ley $\mathrm{N}^{\circ}$ 19.496, que establece normas sobre protección de los derechos de los consumidores.

La Ley $N^{\circ} 19.733$ sobre libertades de opinión e información y ejercicio del periodismo de 4 de junio de 2001

Ley $\mathrm{N}^{\circ} 19.628$ sobre protección de la vida privada, de 28 de agosto de 1999.

Ley $\mathrm{N}^{\circ}$ 19.966, que establece un régimen de garantías en salud.

Decreto con fuerza de ley $\mathrm{N}^{\circ} 1$ de 2006, que fija el texto refundido, coordinado y sistematizado de la Ley $\mathrm{N}^{\circ}$ 18.695, orgánica constitucional de municipalidades.

Decreto con fuerza de ley $N^{\circ} 458$ de 1975, que aprueba nueva Ley General de Urbanismo y Construcciones.

Decreto Ley $\mathrm{N}^{\circ}$ 2.222, que sustituye la Ley de Navegación.

Decreto Ley Nº 3.557 de 1980, que establece disposiciones sobre protección agrícola. 